\title{
Blood rheology and proliferative retinopathy in sickle cell-haemoglobin C disease
}

\author{
B. E. SERJEANT, ${ }^{1}$ K. P. MASON, ${ }^{1}$ P. I. CONDON, ${ }^{1}$ R. J. HAYES, ${ }^{2}$ \\ M. W. KENNY, ${ }^{3}$ J. STUART, ${ }^{3}$ AND G. R. SERJEANT ${ }^{1}$ \\ From the ${ }^{1}$ Medical Research Council Laboratories (Jamaica), University of the West Indies, Kingston, \\ Jamaica, the ${ }^{2}$ Tropical Epidemiology Unit, London School of Hygiene and Tropical Medicine, and the \\ ${ }^{3}$ Department of Haematology, The Medical School, University of Birmingham
}

SUMMARY Haematological and rheological (plasma and serum viscosity, whole blood viscosity, and erythrocyte filterability) factors were studied in 31 age-sex matched pairs of patients with sickle cell haemoglobin $\mathrm{C}$ disease with and without proliferative sickle retinopathy (PSR). Patients with PSR had significantly higher mean cell haemoglobin and lower $\mathrm{Hb} F$ levels on average than the matched controls, but the viscosity and erythrocyte filtration indices did not differ between the 2 groups. There was, therefore, no evidence of rheological differences between patients with and without PSR at the time of the study, although transient rheological abnormalities at the time of development of PSR could not be excluded. Prospective longitudinal studies of rheology before, during, and after the development of PSR would be necessary to detect such changes.

Proliferative sickle retinopathy (PSR) is an important complication of sickle cell disease and is a consequence of vaso-occlusion in the peripheral retina. ${ }^{1}$ It occurs most commonly in sickle cell-haemoglobin $\mathrm{C}(\mathrm{SC})$ disease $^{2}$ which is an otherwise generally benign clinical condition. The reasons for the greater prevalence of ocular complications in SC disease are not understood. Preliminary observations which had suggested that the prevalence was related to high haemoglobin levels were not confirmed by further analysis that showed the effect to be entirely secondary to a strong age related trend in haemoglobin level. ${ }^{3}$ Significant haematological relationships that were found with PSR in SC disease included a high mean cell volume (MCV) in males and low fetal haemoglobin $(\mathrm{HbF})$ in both sexes. ${ }^{3}$

There remained the possibility that some determinant of blood flow or viscosity other than those observed on routine haematological examination contributed to this susceptibility to PSR in SC disease. Blood rheology is known to be abnormal in homozygous sickle cell (SS) disease, these patients showing a raised blood viscosity, provided adjustment is made for the low haematocrit, ${ }^{4}$ and a loss of erythrocyte deformability ${ }^{5}$ compared with normal controls.

Correspondence to Dr G. R. Serjeant, Medical Research Council Laboratories, University of the West Indies, Mona, Kingston 7, Jamaica, West Indies.
Similar, but less marked, changes in blood viscosity ${ }^{6}$ and in erythrocyte deformability ${ }^{7}$ have been described in SC disease. These haemorheological abnormalities are of importance in the pathophysiology of the sickle cell disorders, and a study has therefore been made of blood viscosity and erythrocyte deformability in patients with SC disease to determine their relationship with the presence of PSR.

\section{Materials and methods}

The patients were drawn from the sickle cell clinic of the University Hospital of the West Indies, and from a group of peripheral sickle cell clinics operated by the staff of the MRC Laboratories. Patients with PSR were randomly selected (usually the first 4 patients attending each day) from attendances at special sickle cell eye clinics conducted during a 3 week period in August and September 1981. There were 31 patients (14 male, 17 female) and each was matched as closely as possible by date of birth with a patient with SC disease of the same sex in whom recent ophthalmological examination (within one year) had shown no evidence of PSR. Ages ranged from 15 to 52 years in both patients with PSR (mean age 30.9 years) and controls (mean age $31 \cdot 1$ years), and in no case did the age difference within matched pairs exceed 2 years. When possible, controls were studied on the same 


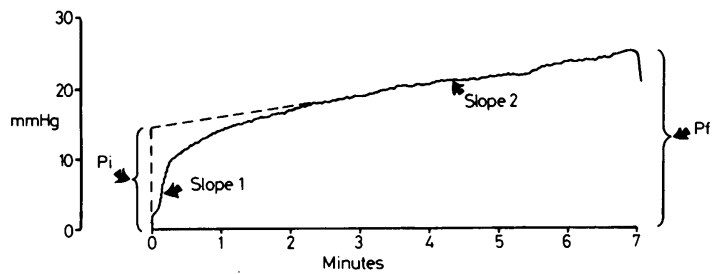

Fig. 1 Example of pressure-time curve, obtained by positive-pressure filtration of washed erythrocytes, to show the 4 readings taken-initial pressure $(P i)$, slope 1, slope 2, and final pressure $(P f)$.

day as the index case and the staff performing the viscosity and filtration studies were unaware of the status of the patient.

Techniques for ocular examination ${ }^{1}$ and for the diagnosis of SC disease ${ }^{2}$ have been previously described. Routine haematological procedures were used. ${ }^{3}$ Plasma fibrinogen was measured by the clot weight method. ${ }^{8}$ Blood viscosity was measured at medium $\left(23 \mathrm{~s}^{-1}\right)$ and high $\left(230 \mathrm{~s}^{-1}\right)$ shear rates in a Wells-Brookfield microviscometer, and serum and plasma viscosity in a Coulter-Harkness capillary viscometer as described elsewhere. ${ }^{9}$ Erythrocyte deformability (filterability) was measured by a positive pressure constant flow system using $5 \mu \mathrm{m}$ pore-diameter polycarbonate membranes (Nucleopore Corporation, Pleasanton, USA), as previously described. ${ }^{9}$ The pressure-time curves were always performed in duplicate, and if disparate were repeated a third or fourth time until reasonable duplicates were obtained.

Four separate readings were taken from each pressure-time curve (Fig. 1). The initial steep slope (slope 1) represented the rise in pressure as the erythrocytes encountered the filter and the second more gradual slope (slope 2) represented the increment in pressure needed to maintain filtration. The initial pressure $(\mathrm{Pi}$ ) was measured in $\mathrm{mmHg}$ by extra- polating slope 2 back to the start of filtration, and the final pressure (Pf) was measured as the pressure in $\mathrm{mmHg}$ reached after 7 minutes of filtration. All 4 parameters were strongly correlated and $\mathrm{Pi}$ and slope 2 were therefore selected to define the characteristics of the curve.

Statistical analysis was by Student's $t$ test and by multiple logistic regression. ${ }^{10}$ Variables with skewed distributions (reticulocytes, $\mathrm{HbF}$, fibrinogen, adjusted whole-blood viscosity at $23 \mathrm{~s}^{-1}$, and slope 2) were transformed as follows: $\log _{e}$ (retics+1), $\log _{e}$ $(\mathrm{HbF}+1), \log _{e}$ (fibrinogen), $\log _{e}\left(23 \mathrm{~s}^{-1}\right)$, and $\log _{e}$ (slope $2+1$ ) to provide approximately normal distributions.

\section{Results}

Comparison of routine haematological indices in patients with and without PSR (Table 1) indicated higher values on average for total haemoglobin $(\mathrm{Hb})$, haematocrit (HCT), mean cell volume (MCV), mean cell haemoglobin (MCH), and mean cell haemoglobin concentration (MCHC), and lower values for reticulocytes and $\mathrm{Hb} F$ in patients with PSR, but only the differences in $\mathrm{MCH}$ and $\mathrm{Hb} \mathrm{F}$ reached statistical significance.

Comparison of the viscosity and filtration values (Table 2) indicated no significant differences between the 2 groups.

Multiple logistic regression analysis was used to explore whether PSR was related to some combination of the variables studied. While this analysis confirmed the association of PSR with low $\mathrm{Hb} F$ and high $\mathrm{MCH}$, no other variable contributed significantly to the fit of the regression model.

\section{Discussion}

The present study has failed to detect rheological differences between patients with SC disease with

Table 1 Comparison of haematological indices (mean and SD) in 31 matched pairs of patients with SC disease with and without PSR

\begin{tabular}{|c|c|c|c|c|c|c|}
\hline & \multicolumn{2}{|l|}{$P S R+v e$} & \multicolumn{2}{|l|}{$P S R-v e$} & \multirow[t]{2}{*}{$t$} & \multirow[t]{2}{*}{ Significance } \\
\hline & Mean & SD & Mean & SD & & \\
\hline $\mathrm{Hb}(\mathrm{g} / \mathrm{dl})$ & $12 \cdot 6$ & $1 \cdot 1$ & $12 \cdot 0$ & $1 \cdot 3$ & $1 \cdot 86$ & NS \\
\hline $\mathrm{HCT}$ & $0 \cdot 343$ & 0.032 & $0 \cdot 328$ & 0.035 & 1.69 & NS \\
\hline $\operatorname{MCV}(f)$ & $84 \cdot 9$ & $6 \cdot 8$ & $82 \cdot 2$ & $5 \cdot 8$ & $1 \cdot 54$ & NS \\
\hline $\mathrm{MCH}(\mathrm{pg})$ & 29.9 & $2 \cdot 4$ & $28 \cdot 3$ & $2 \cdot 8$ & $2 \cdot 48$ & $\mathrm{p}<0.05$ \\
\hline $\mathrm{MCHC}(\mathrm{g} / \mathrm{dl})$ & $36 \cdot 9$ & $1 \cdot 3$ & $36 \cdot 4$ & $1 \cdot 3$ & 1.45 & NS \\
\hline $\log _{e}(\% \text { retics }+1)^{*}$ & $1 \cdot 34(2 \cdot 8)$ & 0.47 & $1.46(3.3)$ & 0.46 & -0.89 & NS \\
\hline $\log _{e}(\% \mathrm{HbF}+1)$ & $0.53(0.7)$ & 0.27 & $0.78(1.2)$ & 0.46 & $-2 \cdot 77$ & $p<0.01$ \\
\hline $\log _{e}$ (g/l fibrinogen) & $1 \cdot 12(3 \cdot 1)$ & $0 \cdot 27$ & $1.08(2.9)$ & $0 \cdot 36$ & 0.46 & NS \\
\hline
\end{tabular}

* Analysis restricted to 28 pairs with complete data.

Figures in parentheses represent mean values re-expressed in original units. 
and without PSR. It could be argued that the techniques for measuring viscosity were relatively insensitive, but it is felt unlikely than an important difference would have been missed.

There was no evidence of hyperviscosity in patients with PSR. Viscosity is directly proportional to the haematocrit, ${ }^{\text {" }}$ and so by inference to the haemoglobin level, but no significant difference in haematocrit, haemoglobin, or whole blood viscosity at high or medium shear rates was apparent between patients and controls. Viscosity at low shear rate was not measured, although plasma and serum viscosities, which reflect intravascular protein concentration, the major determinant of viscosity at low shear, ${ }^{12}$ showed no difference between the 2 groups.

Erythrocyte deformability may be assessed either by measuring high shear blood viscosity when adjusted to a standard haematocrit, or by erythrocyte filterability. ${ }^{12}$ Erythrocyte filterability is reduced in both SS and SC disease, and since deformability is an important determinant of blood flow in the microvasculature it was logical to examine whether a difference occurred between patients with and without PSR. No difference in deformability could be demonstrated whether assessed as high shear viscosity or as erythrocyte filterability through $5 \mu \mathrm{m}$ pores.

A more serious limitation of the present study was the possible discrepancy in time between the age at development of PSR and the age at the time of the study. It is known that PSR develops at different ages in different patients. ${ }^{13}$ If acute short-lived changes in blood rheology were responsible for the initial development of PSR, these may not have been detectable years later at the time of the study, and such a possibility could only be excluded by prospec- tive longitudinal studies of rheology before, during, and after the initial development of PSR.

Previously recognised haematological differences ${ }^{3}$ between patients with SC disease with and without PSR were confirmed in the present study. A high $\mathrm{Hb}$ $F$ level appears to protect against PSR in both SS ${ }^{14}$ and $\mathrm{SC}^{3}$ disease, the most likely mechanism being inhibition of in-vivo sickling. ${ }^{15}$ It is generally recognised that vaso-occlusive episodes occur more frequently in SS than in SC disease, and the greater prevalence of PSR in SC disease was an unexpected and enigmatic observation. It would be unlikely that the peripheral retinal vasculature would form an exception to this pattern of greater vaso-occlusion in SS disease, and studies in children have confirmed that retinal vaso-occlusion is more common in SS than in SC disease. ${ }^{16}$

The apparent conflict between the observations of greater vaso-occlusion in SS disease yet more frequent PSR in SC disease could be resolved by the different tendencies to autoinfarction in the 2 genotypes. Autoinfarction of PSR is known to occur more frequently in SS disease, ${ }^{13}$ and a similar propensity to autoinfarction could affect the abnormal arteriovenous communications that precede the development of PSR. It might then be possible to envisage several models depending on the tendency to vasoocclusion in the peripheral vasculature. Patients with the highest vaso-occlusive indices would develop extensive retinal vaso-occlusion but not proceed to PSR because of occlusion of the preceding anastomotic circulation. Patients with moderate vasoocclusive indices would develop less extensive retinal ischaemia, but abnormal arteriovenous communications would be more likely to proceed to PSR. Patients

Table 2 Comparison of rheological indices (mean and SD) in 31 matched pairs of patients with SC disease with and without PSR

\begin{tabular}{|c|c|c|c|c|c|c|}
\hline & \multicolumn{2}{|l|}{$P S R+v e$} & \multicolumn{2}{|l|}{$P S R-v e$} & \multirow[t]{2}{*}{$t$} & \multirow[t]{2}{*}{ Significance } \\
\hline & Mean & $S D$ & Mean & $S D$ & & \\
\hline Plasma viscosity (mPas) & 1.66 & 0.08 & 1.67 & $0 \cdot 10$ & -0.67 & NS \\
\hline \multirow{2}{*}{\multicolumn{7}{|c|}{$\begin{array}{l}\text { Whole-blood viscosity (mPas) } \\
\text { at patient's HCT }\end{array}$}} \\
\hline & & & & & & \\
\hline $23 \mathrm{~s}^{-1 * *}$ & 8.91 & 1.83 & $9 \cdot 26$ & 1.99 & -0.66 & NS \\
\hline $\begin{array}{c}230 \mathrm{~s}^{-1 * *} \\
\text { at } 0.45 \mathrm{HCT}\end{array}$ & $5 \cdot 75$ & $0 \cdot 89$ & $5 \cdot 76$ & 0.75 & -0.03 & NS \\
\hline $\log _{e}\left(23 \mathrm{~s}^{-1}\right)$ & $2 \cdot 65(14 \cdot 1)$ & $0 \cdot 15$ & $2 \cdot 70(14 \cdot 8)$ & $0 \cdot 18$ & $-1 \cdot 23$ & NS \\
\hline $230 \mathrm{~s}^{-1}$ & $8 \cdot 62$ & $1 \cdot 18$ & $8 \cdot 24$ & 0.95 & 1.47 & NS \\
\hline \multicolumn{7}{|l|}{ Erythrocyte filterability } \\
\hline $\mathrm{Pi}(\mathrm{mmHg})$ & $12 \cdot 80$ & 3.48 & $12 \cdot 45$ & 3.75 & $0 \cdot 34$ & NS \\
\hline $\log _{e}($ slope $2+1)$ & $0 \cdot 80(1 \cdot 2)$ & $0 \cdot 30$ & $0 \cdot 83(1 \cdot 3)$ & 0.32 & -0.51 & NS \\
\hline
\end{tabular}

${ }^{*}$ Analysis restricted to 29 pairs with complete data.

**Analysis restricted to 30 pairs with complete data.

Figures in parentheses represent mean values re-expressed in original units. 
with minimal vaso-occlusion would be less likely to develop retinal ischaemia and therefore unlikely to develop PSR. Patients with SC disease would resemble the model with moderate vaso-occlusive indices.

Further attention should be directed at the determinants of autoinfarction, and the proposed hypothesis of 3 models according to vaso-occlusive index is amenable to testing.

\section{References}

1 Condon PI, Serjeant GR. Ocular findings in homozygous sickle cell anemia in Jamaica. Am J Ophthalmol 1972; 73: 533-43.

2 Condon PI, Serjeant GR. Ocular findings in hemoglobin SC disease in Jamaica. Am J Ophthalmol 1972; 74: 921-31.

3 Hayes RJ, Condon PI, Serjeant GR. Haematological factors associated with proliferative retinopathy in sickle cell-haemoglobin C disease. Br J Ophthalmol 1981; 65: 712-7.

4 Chien S. Rheology of sickle cells and erythrocyte content. Blood Cells 1977; 3: 283-303.

5 Lessin LS, Kurantsin-Mills J, Weems HB. Deformability of normal and sickle erythrocytes in a pressure-flow filtration system. Blood Cells 1977; 3: 241-62.
6 Self F, McIntire LV, Zanger B. Rheological evaluation of hemoglobin S and hemoglobin C hemoglobinopathies.J Lab Clin Med 1977; 89: 488-97.

7 Messer MJ, Harris JW. Filtration characteristics of sickle cells: rates of alteration of filterability after deoxygenation and reoxygenation, and correlations with sickling and unsickling. $J \mathbf{L a b}$ Clin Med 1970; 76: 537-47.

8 Ingram GIC. A suggested schedule for the rapid investigation of acute haemostatic failure. J Clin Pathol 1961; 14: 356-60.

9 Serjeant BE, Mason KP, Kenny MW, et al. Effect of alpha thalassaemia on the rheology of homozygous sickle cell disease. BrJ Haematol 1983; 55: 479-86.

10 Holford TR, White C, Kelsey JL. Multivariate analysis for casecontrol studies. Am J Epidemiol 1978; 107: 245-56.

11 Dormandy JA. Clinical significance of blood viscosity. Ann $R$ Coll Surg Engl 1970; 47: 211-28.

12 Stuart J, Kenny MW. Blood rheology. J Clin Pathol 1980; 33: 417-29.

13 Condon PI, Serjeant GR. Behaviour of untreated proliferative sickle retinopathy. Br J Ophthalmol 1980; 64: 404-11.

14 Hayes RJ, Condon PI, Scrjcant GR. Hacmatological factors associated with proliferative retinopathy in homozygous sickle cell disease. Br J Ophthalmol 1981; 65: 29-35.

15 Serjeant GR. Fetal haemoglobin in homozygous sickle cell disease. Clin Haematol 1975; 4: 109-22.

16 Talbot JF, Bird AC, Serjeant GR, Hayes RJ. Sickle cell retinopathy in young children in Jamaica. Br J Ophthalmol 1982; 66: 149-54. 